

\title{
GOA, OS ÍNDIOS NO BRASIL E A OBRA DE JOHN MANUEL MONTEIRO*
}

\author{
OMAR RIBEIRO THOMAZ
}

A verdadeira generosidade para como futuró dar tudo de si no presente. Albert Camus

[*] Agradeço carinhosa e especialmente a Thomas Monteiro, a quem conheci ainda criança eque é hoje um historiador com todas as letras, como seus pais. Nos últimos meses, pudemos conversar sobre John Monteiro e ficou evidente que temos um imenso trabalho pela frente, não apenas no que diz respeito a reunir e disponibilizar sua obra, como também no sentido de elucidar enigmas deixados por John ao longo de sua trajetória pessoal e intelectual.

[1] Para além da obra escrita e de seu trabalho como orientador, Jonh era responsável por um site de história indígena e do indigenismo e colaborou com obras audiovisuais, como Histórias do Brasil, exibida pela TV Brasil em 2011.

[2] Em 1978, John Monteiro concluiu, sob a orientação de Peter Blasenheim, sua monografia de graduação - Portuguese colonization in the tropics: Afonso de Albuquerque's marriage plan in Goa -, realizada no Colorado College. Esta pequena e inédita pérola em breve será publicada.

Da dolorosa sensação da perda à da saudade serena há longo caminho de idas e vindas. Quando a perda é inesperada, o desalento ressurge quando menos se espera, em expressões de incredulidade ou manifestações de impotência. A perda de um amigo e companheiro de trabalho exige, como outras, um percurso de elaboração: lembranças socializadas com amigos comuns, silêncios cheios de sentido e olhares perdidos no vazio mais tempo do que o devido. Mas a perda de um amigo intelectual oferece sempre a possibilidade de reencontros no revisitarde sua obra.Éo caso de John Monteiro, que nos abandonou de forma abrupta em março de 2013.

Chegará o momento da releitura sistemática da obra de John Monteiro, um balanço de sua contribuição decisiva para a história dos índios no Brasil expressa em livros, artigos, conferências e textos inéditos de sua autoria, mas não só: seu legado está nos trabalhos de um significativo grupo de orientandos e orientandas que, espalhados em sua maioria pelo Brasil e outros países da América Latina, carregam consigo o compromisso apreendido na convivência com o professor e orientador ${ }^{1}$. Sua generosidade, contudo, tornou-o interlocutor de diálogos insuspeitos realizados em grupos de trabalhos de congressos e seminários, em bancas de tese e no dia a dia das instituições nas quais trabalhou.

O propósito aqui - uma breve especulação em torno das relações de seu trabalho sobre a história dos índios no Brasil no processo colonial e sua reflexão primeira, da mesma natureza, sobre as relações entre portugueses enativos em terras de Goa no século XVI² - merece um preâmbulo que, de natureza pessoal, pretende recuperar facetas da trajetória e da atuação de John que tiveram grande impacto em todo 
um grupo de pesquisadores, entre filósofos, historiadores, antropólogos e sociólogos, parte de uma mesma geração.

II

Tive o privilégio de conhecer pessoalmente John Monteiro no Centro Brasileiro de Análise e Planejamento quando, em 1992, ingressei no Programa de Formação de Quadros Profissionais. Naquela altura,e para desespero de alguns daqueles que reivindicavam relações mais ou menos densas com o já mítico "grupo do Capital"3, muitos de nós, por razões variadas, propusemos um grupo de estudos do pensamento social brasileiro, que, coordenado por John Monteiro, durou muitos anos e teve um impacto central em várias dissertações e teses de doutorado em curso. Do grupo participaram ativamente Vinícius Figueiredo e Felipe Chaimovich, da filosofia; Angela Alonso, da sociologia; Miriam Dolhnikoff, Pedro Puntoni e Íris Kantor, da história; eu, Fernanda Peixoto e Luiz Donisete Grupioni, da antropologia. Também frequentava o grupo Maria Helena Machado e, eventualmente, convidávamos Luiz Felipe de Alencastro, Roberto Schwarz e Rodrigo Naves.

Ouso dizer que, naquela altura, não fomos precisamente originais. Não eram poucos os grupos que, entre finais dos anos 1980 e início dos anos 1990, em distintas partes do Brasil, propunham uma leitura mais generosa de autores como Gilberto Freyre ou Oliveira Vianna, após concorrentes e sucessivos grupos do Capital - havia muitos, e não apenas aquele que se quer único, rigoroso, mítico, original e paulista - que, entre os anos 1950 e 1980, se dedicaram a erguer uma ciência social no Brasil científica por sobre as supostas ruínas de ensaios especulativos que deveriam ser evitados, criticados e destruídos ${ }^{4}$.

Mas se o nosso grupo foi inicialmente bastante ordinário, tornou-se original progressivamente. Sobretudo pela coordenação firme e discreta do então jovem historiador que havia poucos anos retornara ao Brasil, John Manuel Monteiro5. Isso porque John não se contentava com o que se afirmava a torto e a direito pelos corredores da Faculdade de Filosofia, Letras e Ciências Humanas da UsP — onde fazia meu doutoramento junto ao programa de antropologia social — sobre a suposta especificidade do pensamento social no Brasil ${ }^{6}$. Sua formação latino-americanista lançava luz a uma forma de refletir sobre e no Brasil que interagia ativamente com a de outros países latino-americanos em formação. Assim, se líamos Joaquim Nabuco, Nina Rodrigues, Couto de Magalhães, Manuel Bonfim, Alberto Torres, Oliveira Vianna, Gilberto Freyre, Caio Prado Júnior e Sérgio Buarque de Holanda, foi John que nos trouxe Facundo, de Domingos Faustino Sarmiento, Ariel, de José Henrique Rodó, e Hombres de Maíz, de José Vasconcelos, Ainsi parla l'oncle, de Jean Price-Mars, entre tantas outras obras que nos

\begin{abstract}
[3] Sobre o "grupo do Capital" cujas reuniões sistemáticas se realizaram entre a segunda metade dos anos 1950 e início dos anos $1960 \mathrm{e}$ do qual faziam parte, entre outros, intelectuais como Fernando Novais, Fernando Henrique Cardoso, Octávio Ianni, Francisco C. Weffort, José Arthur Giannotti e Paul Singer muito se escreveu. Não cabe, no espaço deste artigo, qualquer forma de debate sobre essa geração intelectual, salvo destacar que a gênese do próprio Cebrap e de parte de seus rituais estão, muitas vezes, ligadas à dinâmica daquele grupo que, nessa instituição, conserva parte de seus membros originais e uma grande quantidade de colegas que reivindicam direitos sucessórios.
\end{abstract}

[4] Nesse processo, muitos se esqueceram de como se pode escrever bem em português, uma das características da tradição ensaística nacional.

[5] John Monteiro nasceu em St. Paul, em Minnesota, Estados Unidos, e entre os oito e os quinze anos viveu com sua família em Campinas, São Paulo, retornando aos Estados Unidos após um período na Colômbia.

[6] Na altura (e um pouco até hoje) era recorrente um certo delírio historiográfico e sociológico em torno da especificidade do Brasil e sua formação. Ora, a assertiva ou é banal todos os processos formativos são específicos -, ou exige comparações mais ou menos sistemáticas, o que revelaria sua falta de originalidade. Pensando em contextos latino-americanos ou pós-coloniais, ideais de superação expressos em mestiçagens, hibridismos etc., ou processos de invenção, exclusão, eliminação ou consolidação de minorias são, evidentemente, recorrentes. 
obrigavam a rever a propalada em verso e prosa originalidade, especificidade ou organicidade do pensamento nacional. Sem clara consciência, e sob a batuta de John Monteiro, retomávamos algo que interpelara alhures autores como Antonio Candido ou Florestan Fernandes, e que tinha sido deixado solenemente de lado por gerações intelectuais ulteriores, particularmente em São Paulo: relações efetivamente dialógicas com intelectuais de outros países latino-americanos e caribenhos.

\section{III}

[7] O trabalho de John Monteiro sobre a obra de Alfredo Ellis Júnior, cuja publicação passou relativamente despercebida é, hoje, referência para todos os que trabalham com história indígena no sudeste do Brasil ou com outros episódios da história paulista. Cf. Monteiro, John. "Caçando com gato: raça, mestiçagem e identidade paulistana na obra de Alfredo Ellis Júnior". Novos Estudos, São Paulo, $\mathrm{n}^{\circ} 38$, março de 1994 (pp. 79-88). Antes de ser publicado, o texto foi calorosamente discutido no seminário temático Raça e Mestiçagem no Pensamento Social Brasileiro, na ANPOCS, em outubro de 1993, do qual participaram, entre outros, Fernanda Peixoto, Lilia Schwarcz, Luis Donisete Benzi Grupioni, Maria Helena Machado, Pedro Puntoni, Ricardo Benzaquen de Araújo, Vinícius Figueiredo e Omar Ribeiro Thomaz.

[8] Não posso deixar de lembrar nosso deslumbramento ao irmos além de Raízes do Brasil - na altura texto canônico para os estudantes de ciências sociais (os de história certamente liam a obra de Sérgio Buarque de Holanda com mais generosidade e inteligência). Os que estudávamos antropologia nos fascinávamos com passagens de Monções e Caminhos e fronteiras, que remetiam diretamente à então recente obra de Marshall Sahlins, Ilhas de história.

[9] Monteiro, John Manuel. Negros da terra: índios e bandeirantes nas origens de São Paulo. São Paulo: Companhia das Letras, 1994.
Essa guinada latino-americana era observada de longe, mas com certo interesse, por colegas da USP e do Cebrap; afinal, ler os latino-americanos e caribenhos significava, no mínimo, uma pequena dose de cosmopolitismo. Um cosmopolitismo de segunda, mas ain$\mathrm{da}$ assim, cosmopolitismo. O que gerava reações furiosas era quando John propunha a leitura de autores não apenas reconhecidamente menores - e sobre quem John Monteiro jamais reivindicou maioridade! - mas efetivamente esquecidos, como Alfredo Ellis Júnior, entre outros paulistanos devidamenteenterrados pelas pás da Faculdade de Filosofia7. Aqui cabem, pelo menos, duas perguntas: por que John lia, debatia e publicava sobre Alfredo Ellis Júnior e seus contemporâneos paulistas e por que isso gerava tanta hostilidade entre os verdadeiros e nobres herdeiros da Maria Antonia?

Sem dúvida, sua leitura de Alfredo Ellis Júnior e outros acadêmicos paulistas devia-se a seu interesse histórico e historiográfico pelas formas, materiais e retóricas de incorporação, exclusão e extermínio das populações indígenas na região de São Paulo entre os séculos XVI e XVII. Afinal, foram esses autores que sistematizaram as fontes sobre a ocupação e as idas e vindas das fronteiras dos sertões paulistas - o que englobava o Paraná, partes do Mato Grosso do Sul, Minas Gerais e mais além. Os mesmos autores trabalhados em obras mestras de Sérgio Buarque de Holanda como Monções, A expansão paulista entre fins do século XVI e princípios do século XVII e Caminhos e fronteiras, as quais também foram preteridas e por vezes esquecidas em prol de seu ensaio inaugural, Raizes do Brasil ${ }^{8}$. John encarava esses autores, destacava meandros ignorados, sugeridos ou pouco trabalhados por Sérgio Buarque de Holanda, e caía na boca (de parte) do povo da FFLCH que, herdeiros da Maria Antonia, tinham transformado as bandeiras - capítulo decisivo da história dos índios no Brasil - num episódio menor. Por sorte, John nunca deu muita bola aos comentários jocosos que se faziam a esse respeito e seguiu seu trabalho, escrevendo no Cebrap a versão final em português do seu monumental Negros da terra9. 
Mas cabe aqui pelo menos especular não só sobre o porquê de John seguir em frente, mas também sobre as razões da fúria de alguns uspianos diante da empreitada. Alfredo Ellis Júnior e suas gloriosas bandeiras dos anos pós-revolucionários da década de 1930 paulista lembravam algo que os paulistanos da Faculdade de Filosofia - comprometidos com a reinvenção da inexpressiva Semana de 22, com a modernidade da rede Tupi de Televisão e com o MASP, construído pelo fofoqueiro e mau caráter Assis Chateaubriand queriam esquecer: que São Paulo era provinciana e tacanha e que de certa forma, ao contrário de suas pretensões senão miméticas com o resto do Brasil, como desejava o Rio de Janeiro (pelo menos até hoje alguns cariocas), certamente de proa e vanguardistas, continuava sendo o que sempre foi, uma parte do Brasil, até bem recentemente, insignificante intelectual e institucionalmente e, com toda a certeza, longe de qualquer sorte de centralidade. Enfim, não seríamos mais do que uma região entre outras.

IV

Mas onde entra Goa nisso tudo? Aqui vale a pena explorar alguns detalhes biográficos de John Monteiro, o que não é propriamente fácil, pois uma de suas características era, definitivamente, a discrição. Espremendo a memória de duas décadas de convivência afetiva, intelectual e institucional - trabalhei com John Monteiro no Cebrape logo no Departamento de Antropologia da Unicamp - e a partir de conversas com pessoas queridas, com destaque para seu filho, Thomas Monteiro, pude levantar alguns pontos que podem nos indicar pistas de uma trajetória que, longe de ser linear ou evidente, conecta as inquietações de John Monteiro com territórios do antigo império colonial português.

John Monteiro esteve algumas vezes em Goa, onde estabeleceu contatos intelectuais com acadêmicos do Centro de Estudos Latino-americanos da Universidade de Goa - acalentávamos o desejo de efetivar intercâmbio de professores e alunos com a universidade - e realizou atividades de pesquisa neste estado da União Indiana, para além de suas incursões nos arquivos portugueses ou naqueles disponíveis em universidades norte-americanas. Para os que convivemos com John, era evidente o papel central de Goa em sua vida espiritual, sobre a qual, em função de seu caráter estritamente privado, não me sinto no direito de especular. Alguns detalhes de sua história familiar, contudo, nos permitem construir nexos entre essas paragens índicas, outrora fragmentos do império colonial português, com outros tantos fragmentos históricos e territoriais sobre os quais John conversava com extraordinária vivacidade, erudição e comodidade. 
Ao contrário do que pensei por anos, a família de John Monteiro não era de origem açoriana. Recentemente, em meio a histórias de baleeiro, John me contou que, de fato, era de origem cabo-verdiana. Seus avós paternos teriam nascido em algumas das ilhas de Cabo Verde e abandonado, como tantos outros, este arquipélago vítima de fomes regulares. No início do século XX, estabeleceram-se em New Bedford, na costa oeste norte-americana, como tantos cabo-verdianos, açorianos e portugueses continentais. Seus avós viveram num verdadeiro gueto cabo-verdiano e tiveram uma dura vida de trabalhadores agrícolas. Para superar as barreiras de nacionalidade e raça, seu avô se alistou no exército norte-americano. Morreu quando seu navio veio a pique sob bombardeio da Tríplice Aliança em plena Primeira Guerra Mundial. Seu filho, Manuel, nascido norte-americano, portava em sua certidão de nascimento sua marca de origem e foi classificado como "negro". Sua raça e seu nome pareciam destiná-lo a uma vida de privação no contexto norte-americano da primeira metade do século XX, não fossem dois elementos cruciais na vida do velho Manuel, pai de John Manuel Monteiro: uma guerra e um casamento.

Com efeito, o desejo de inserção num contexto social hostil fez com que Manuel tomasse duas decisões diretamente ligadas a um projeto de ascensão social: assumir outro nome, James (parece que, ao longo de sua vida, poucos viriam a conhecer seu verdadeiro nome), e alistar-se no exército norte-americano. Destinado aos duros campos de batalha europeus da Segunda Guerra Mundial o outrora negro Manuel progressivamente se transforma em James e conhece sua futura esposa, filha de alemães que acompanha o exército norte-americano como enfermeira na guerra contra a pátria de seus pais.

Quando retorna da guerra europeia, casa-se e começa a trabalhar na empresa do sogro, inicialmente em cargos subalternos e progressivamente assumindo funções diretivas. James parecia confirmar o sonho americano de sucesso e ascensão social.É nesse contexto, em St. Paul, Minnesota, que nasce John, que, se traz no primeiro nome a realização do pai, no segundo, Manuel, a lembrança de seu passado que surgiria de forma discreta, mas crescente, no futuro. Se do pai herda o nome, a mãe deixa-lhe como legado o protestantismo (luteranos?), assumido, por outro lado, por seu próprio pai, James (Manuel).

Sobre a infância de John Monteiro, seus pais e irmãos, sabemos pouco. Quando tinha por volta de oito anos, nos anos 1960, seu pai transforma-se num executivo internacional e, fazendo valer seus conhecimentos da língua portuguesa, se estabelece por alguns anos em Campinas, trabalhando na multinacional $3 \mathrm{M}$. Dos oito aos quinze anos, John Monteiro vive em Campinas, sem sequer imaginar que viria a trabalhar no Departamento de Antropologia e junto ao Programa de Pós-Graduação em História dessa universidade anos depois! Das 
memórias familiares desse primeiro período campineiro ficou a hostilidade da comunidade americana que então vivia na cidade paulista: hostilidade diante de um negro que se queria branco e norte-americano na pujante e racista sociedade da cidade paulista.

Aos quinze anos, começa seu retorno aos Estados Unidos, com uma passagem anterior pela Colômbia, período em que consolida seus conhecimentos de língua espanhola. Sua primeira inserção na vida acadêmica norte-americana se dá no curso de História da Universidade do Colorado, onde apresenta como monografia de conclusão seu trabalho sobre Afonso de Albuquerque e suas políticas na Goa portuguesa do século XVI. Trata-se do início de seu caminho de volta, um retorno a fragmentos de uma história que, evidente no nome, dele não podia se separar.

\section{V}

Goaé sua primeira porta de entrada em um universo de problemas históricos que conectavam um arquipélago disperso por distintas partes do território americano, enclaves africanos e grandes portos orientais.Aexpansão portuguesa (e não só) nos séculos XV,XVI eXVII, entre o Pacífico, o Índico e o Atlântico propõe enigmas que resistem a grandes esquemas, os quais são percebidos porJohn logo de entrada: o andar da carruagem só ganha sentido se compreendemos não apenas aqueles que durante séculos se afirmaram como agentes da colonização - e da história. Não se tratava - em Goa do século XVI ou em São Paulo do século XVII — da realização de uma etno-história.A história só fazia sentido se, de fato, incorporasse os sentidos de um império que não se restringia aos projetos e interpretações dos que se consideravam seus promotores. As políticas em Goa, que implicaram trocas e alianças matrimoniais entre os representantes da Coroa portuguesa e as populações, fez com que a lógica da colonização não se reduzisse a uma geopolítica da mestiçagem, uma boa ideia que, como desconfiava John Monteiro, não explicava tudo, sobretudo naquelas partes que se transformaram em sua gênese ou progressivamente nas menos atraentes do império colonial português - o Vice-reino da Índia portuguesa, São Paulo ou os prazos zambezianos.

São Paulo dos séculos XVI e XVII, cujo passado John reconstrói com maestria devolvendo o que lhe cabe de agência às populações indígenas ${ }^{10}$, e apesar das insistências mitológicas dos quatrocentões, apenas e com muito esforço se adivinha nos dias atuais. No entanto, em Goa a coisa foi diferente. Eis o que marcava nossos debates sobre o Estado da Índia portuguesa: sua crescente marginalidade a partir do século XVII no contexto do império colonial português promoveu a reprodução de um universo social cuja continuidade ver-se-ia violentamente interrompida em dezembro de 1961.

\footnotetext{
[10] Tive a oportunidade de acompanhar a brilhante aula sobre a noção de índio colonial defendida por John Monteiro em sua tese de professor titular junto ao Departamento de Antropologia da Unicamp.
} 
Mas as conexões entre os textos paulistas e aqueles que se elaboraram em e sobre Goa pareciam fazer sentido. Fazendo pesquisa na Biblioteca Velha do Museu Nacional, me deparei com a coleção completa dos Arquivos da Escola Médico-Cirúrgica de Nova Goa, cuja publicação foi quase contínua entre meados do século XIX e 1961. Ao longo do período que me interessava — os anos 1930 e 1940 - um intelectual goês destacava-se, Alberto Germano da Silva Corrêa. Seu labor nessa escola era mais próximo àquela mescla de médico, antropólogo físico e historiador que acaba por elaborar contundentes conclusões de extremo interesse para a antropologia social em sua obsessão na descrição de processos históricos que culminariam no surgimento de novos tipos humanos frutos de mestiçagens de toda ordem.

Eis que, para além de vários artigos deste autor da fina flor da elite brâmane católica goesa sobre a mestiçagem entre brancos e negros em Angola e Moçambique, bem como sobre o tipo goês ariano cujas origens estariam no século XVI de Afonso de Albuquerque, encontramos nos arquivos uma extensa correspondência entre Germano Corrêa e Oliveira Vianna, na altura às voltas com as populações do Brasil meridional, ou seja, entre outros, os paulistas. Um e outro autor baseavam-seem supostos eugênicos para sacar suas conclusões sobre paulistas e goeses; um e outro mobilizavam uma erudição histórica impressionante sobre os primeiros anos de presença portuguesa no Oeste indostânico e no sul do Brasil.

Esse achado acabaria por dar origem a muitas conversas entre John e eu, na qual sempre saía impressionado com sua erudição, que se apresentava sempre suavemente e sem qualquer forma de autocelebração. Conversamos muito sobre possíveis relações entre o concani sistematizado e língua veicular em Goa e o tupi geral, falado extensamente em São Paulo até pelo menos fins do século XVIII. Não foram poucas as vezes que as conversas acabavam no Cantinho de Goa, restaurante ponto de encontro dos goeses de Goa e de Moçambique em São Paulo, onde o tema da invasão/anexação/libertação de Goa e a consequente radicalização da desterritorialização dos goeses (e o fim de Goa) se impunha. Em meados dos anos 1990, começava a ficar evidente que os acontecimentos de Goa em 1961 diziam respeito exclusivamente a esse território: estávamos longe de uma espécie de modelo que poderia explicar a invasão indonésia do Timor Oriental (como ficou claro na independência desse país) ou na incorporação de Macau pela China socialista.

E dessas conversas, tantas ideias de projetos não realizados! Em todos eles, viagens a Goa previstas! Meu interesse crescente pela Escola Médico-Cirúrgica de Nova Goa e seu lugar na formação da administração colonial portuguesa do século XX encontrava pleno equilíbrio com o interesse de John na Velha Goa do século XVI que tanto parecia 
sugerir para a compreensão dos acontecimentos paulistas do mesmo período. Em todos os casos, nosso interesse ia para o que não existe: aquela São Paulo de índios e paulistas, aquela Goa de goeses, parses, muçulmanos e hindus. Isso sim: em nenhum de nós havia uma pisca de nostalgia, mas uma imensa curiosidade.

No ambiente denso e tenso do debate intelectual paulistano, em meio a rituais mais performáticos do que realmente de sacrifício (afinal, pouco ou nenhum sangue rolava), as observações e comentários do John se destacavam. Poucos sabiam das peripécias de sua história familiar e para muitos o Manuel soava certamente provinciano, como soem considerar supostos cosmopolitas tudo o que diga respeito a Portugal. Ninguém sabia que o Manuel nos levava a uma história infinitamente mais interessante do que aquelas dos representantes de elites ora acomodadas e francamente pouco desafiadas. Os comentários discretos de John oscilavam entre o desafio aos acomodados e a generosidade para tantos manés que surgiam no seu caminho. Eis o que marcou John em sua trajetória como historiador e professor: a generosidade discreta que abriu infinitas portas para a compreensão de tantos passados esquecidos ou deliberadamenteignorados e para o futuro de tantos que, como o velho Manuel, batalham por sua inserção numa sociedade hostil.

OMAR RIBEIRO THOMAZ é professor no departamento de antropologia do IFCH-Unicamp.
Recebido para publicação

em 19 de setembro de 2013.

\section{NOVOS ESTUDOS}

CEBRAP

97 , novembro 2013

pp. 5-12 
